originally proposed, and there can be little doubt that this was contrary to the main trend of current opinion. This statement requires some qualification. $\mathrm{He}$ did not suggest that all characters were acquired or that all acquired characters were transmitted; but, and this is an important distinction, he did suggest that there was evidence, experimental and other, to show that in certain instances changes induced by external forces in the parent could be handed on to the offspring even if in a modified form. As a corollary there is the possibility that the blind acceptance of the opposite point of view will lead to overlooking or misinterpreting evidence. That these opinions were honestly held no one doubted, and when they were put forward without rancour, with his wide knowledge and his cogency, even if they did not always convince, they certainly caused his opponents to pause and take stock of their position. Such jolts to the complacent acceptance of the orthodox are of considerable value. His ideas were by no means all heterodox, and by his clear exposition of both fact and theory he had considerable influence on contemporary zoological thought in Great Britain.

Although not a large man physically, one had only to be in MacBride's presence for a short while to realize that he had a dynamic personality and a well-stored mind. In meetings and in private discussions, no matter how widely the talk might range over the whole field of zoology, he had always a pertinent contribution to make. He has left a memory of untiring energy and remarkable knowledge, and those bodies and institutions that he served will also recall his loyalty and devotion so freely given.

There is another side to his life, although this is not the place to enlarge upon it. He was devoted to his family and in recent years settled down to a wellearned retirement in Alton, Hampshire. Here he had a delightful garden and was much interested in country life, in the affairs of his locality and in the parish church. To his widow we should like to extend our sincere sympathy.

\section{Dr. F. L. Arnot}

News has been received from Sydney, Australia, of the sudden death early in October of Dr. Frederick Latham Arnot, for eight years lecturer in natural philosophy in the University of St. Andrews and, since 1939, lecturer in physics in the University of Sydney. He was born on September 29, 1904, at Sydney, of British parents, his father being Scottish and his mother English. He was educated in his home University, and after graduating with firstclass honours in 1927, he was awarded an exhibition at Trinity College, Cambridge, and worked as a research student in the Cavendish Laboratory under the supervision of Sir Ernest Rutherford (later Lord Rutherford). Two years later he was awarded an Isaac Newton studentship, and received the degree of Ph.D. in June, 1930, for investigations concerning the collisions of slow electrons with molecules in gases at low pressures. His later results at Cambridge on the scattering of electrons in gases and on the diffraction of electrons in mercury vapour were of great beauty and importance.

In 1931, Arnot was appointed to a lectureship in the United College of the University of St. Andrews, and in association with his fellow-workers in the physical laboratory carried out valuable experimental work on ionization in gases and vapours. In these investigations new processes of ion formation were discovered, in particular Arnot's theory of negative ion formation at metal surfaces being of outstanding importance. The results obtained have important bearings on technical problems, and are of interest in connexion with the formation of negative ions in the outer regions of the earth's atmosphere.

In 1939, he was approved for the degree of Sc.D. by the University of Cambridge at an unusually early age. He was offered and accepted a lectureship in physics in the University of Sydney, and in July Dr. and Mrs. Arnot left St. Andrews for Australia. After his arrival he at once set about the organization of research work with the assistance of advanced students, and commenced investigations on nuclear physics and cosmic ray phenomena. Mention should also be made of the great interest which he took in problems of cosmology, and a preliminary account of his views, admittedly of a somewhat speculative character, was published in NATURE of June 25, 1938. His many friends in all parts of the world deeply regret the untimely close of a promising career.

H. S. Allen.

\section{Prof. Julius Wagner-Jauregg}

A BRIEF announcement of the death at the age of eighty-three of Prof. Julius Wagner, Ritter von Jauregg, the eminent Viennese medical man who introduced inoculation of malaria as a treatment for general paralysis, appears in the October 5 issue of the Schweizerische Medizinische Wochenschrift.

Like his predecessor Kraft-Ebing (see Nature, August 10, p. 194), he was born at Wels in Upper Austria, on March 7, 1857. He received his medical education at the University of Vienna, where his chief teachers were Stricker, professor of general and experimental pathology, and Leidesdorf, professor of psychiatry. He qualified in 1880 and five years later became lecturer in neurology and psychiatry at his Alma Mater. During 1889-1893 he was extraordinary professor of neurology and psychiatry at Graz, and was then appointed professor in this subject at Vienna, where he remained until his retirement in 1928.

His early work was connected with the treatment of cretinism with thyroid extract, and of goitre with small doses of iodine. His most important achievement, for which he received a Nobel Prize in 1927, was the inoculation of benign tertian malaria for the treatment of general paralysis, which, though not devoid of risk, proved successful in about a third of all cases of this hitherto invariably fatal disease. The same treatment was afterwards applied in tabes. The method had been suggested to him by beneficial effects in various psychoses of pyretogenic substances, 